\title{
Dynamic Monitoring and Stability Analysis of Rock-bolted Crane Girder In large Cavern With Layered Surrounding Rock
}

\author{
Jing Liu ${ }^{1,2}$, Xiaomin Liu ${ }^{1,2}$, Shengjie $\mathrm{Di}^{1,2, \mathrm{a}}$ and $\mathrm{Xi} \mathrm{Lu}^{1,2}$ \\ ${ }^{1}$ Northwest Engineering Corporation Limited, Power China, Xi'an, Shanxi, 710065, China \\ ${ }^{2}$ High Slope and Geological Hazard Research \& Management branch, National Energy and Hydropower Engineering Technology R\&D \\ Center, Xi'an, Shanxi, 710065, China
}

\begin{abstract}
The large and medium-sized hydropower projects underground cavern group are basically in relatively integrate surrounding rock, so there are few engineering examples in layered surrounding rock with type III surrounding rocks as the main rock, and lack of successful experience. According to rock-bolted crane girder under the layered surrounding rock of a large underground power station, analyzing prototype dynamic monitoring data of the excavation, unloading and load-bearing test. The distribution of the monitoring data conforms to the normal law, and there are no large outliers, under the action of a large number of bolts, rock-bolted crane girder basically forms a good integrity with the layered surrounding rock, and the load-bearing test has no effect on the stress condition and stability condition of surrounding rock.
\end{abstract}

\section{Introduction}

Rock-bolted crane girder is one of the load-bearing structures of lifting equipment used in mechanical and electrical installation of underground powerhouse. It uses anchors to anchor cast-in-situ concrete crane beams to the rock mass, and the load contacts the rock through the anchor rod and concrete beam The interaction on the surface is transmitted to the rock mass, making full use of the bearing capacity of the surrounding rock.

Rock-bolted crane girder is one of the load-bearing structures of lifting equipment used in mechanical and electrical installation of underground powerhouse, the load is transmitted to the rock mass through the interaction between the anchor and the concrete beam, making full use of the bearing capacity of the surrounding rock. In the 1980s, rock-bolted crane girder was first applied in Norway underground powerhouse [1], and achieved good results, Later, it was used in Sweden, Japan and other countries. In 1986, China was first used in Yunnan Lubuge hydropower station, later, rock-bolted crane girder structure was adopted in the underground powerhouse of Longtan, Xiaolangdi, Three Gorges and so on [2].

Engineering practice shows [3,4], during the excavation of the middle and lower caverns, the surrounding rock around the cavern is deformed due to the excavation stress release, and rock-bolted crane girder also deforms with the surrounding rock. At present, the large and medium-sized hydropower projects underground cavern group are basically in relatively integrate surrounding rock, so there are few engineering examples in layered surrounding rock with type III surrounding rocks as the main rock, and lack of successful experience. Layered lithology [5] is a fragmented sedimentary rock with thin lamellar or thin layered bedding, it is easy to crack into fragments with hard objects, and surrounding rock mechanical parameters are complex.

In this paper, rock-bolted crane girder of underground powerhouse with layered surrounding rock is analyzed by dynamic monitoring method, and the state of rock-bolted crane girder under layered surrounding rock is made clear in the unloading and bearing operation of cavern, so as to ensure engineering safety. This paper also provides the important data reference for the same type of project.

\section{Support Engineering}

A Hydropower Station project is one of the Lancang River cascade hydropower stations. It uses the underground water diversion power generation system on the right bank. The underground powerhouse caverns are large in scale and the geological conditions are complex. The rock-bolted crane girder is arranged in upstream and downstream of the underground powerhouse, which belongs to the typical layered surrounding rock structure. The side walls reveal that the surrounding rocks are interbedded with sandy slate and metamorphic sandstone, the rock mass is fresh and slightly weathered, and the cavern walls are dry. The main types are III1 III2 surrounding rocks. Figure 1 is a photo of the support engineering rock-bolted crane excavation face.

Figure 2 is section shape and anchor design of the rock-bolted crane girder. the design section is $2.1 \times 2.4 \mathrm{~m}$, two rows of tension anchor (Ф32, PSB830), about $10 \mathrm{~m}$

\footnotetext{
*Corresponding author: ${ }^{\text {a } 14276804 @ q q . c o m}$
} 
into the rock, one row of compression anchor ( $\Phi 32$,

HRB400), about $7.5 \mathrm{~m}$ into the rock.

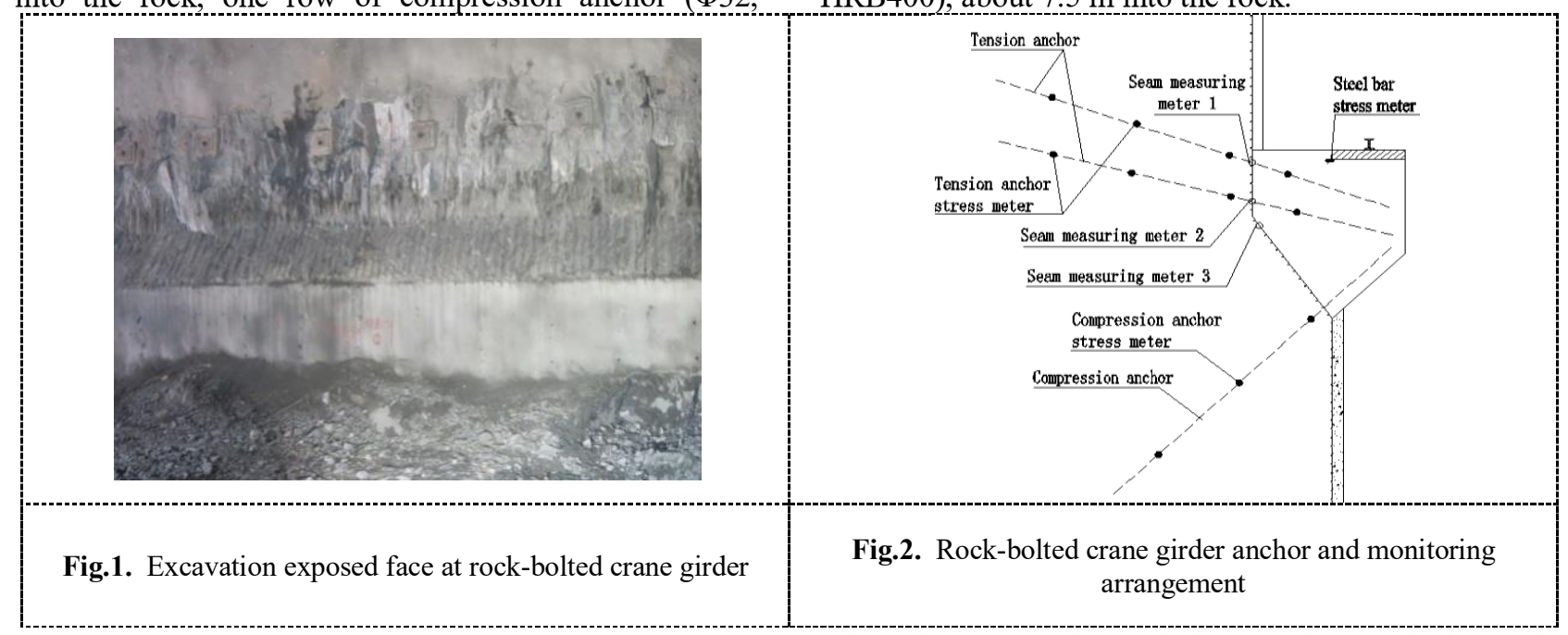

\section{Prototype dynamic monitoring}

The prototype monitoring items of rock-bolted crane girder mainly include: opening and closing values of seam meter monitoring, steel bar stress monitoring, anchor stress monitoring. Through analyzing the monitoring data of rock-bolted crane girder different construction stages and working stages, the stress and deformation of anchor beam are mastered, and then the safety and stability of rock-bolted crane girder in each stage are evaluated, and the engineering measures are followed up in time, secure dynamic control.

\section{Monitoring instrument Arrangement}

The monitoring section of rock-bolted crane girder is mainly selected at the relatively dangerous places, such as rock-bolted crane girder on the top of diversion tunnel, rock-bolted crane girder on the top of traffic cave, the position of rock-bolted crane girder at the relatively developed crack. The position of rock-bolted crane girder monitoring instrument on the selected section is shown in Figure 2. Including the following: the joint between concrete and rock wall is monitored by the seam measuring meter in 3 places; the anchor adopts the anchor stress meter, the tension anchor arranges 1 measuring point in the concrete and 3 measuring points in the rock, the compression anchor arranges 3 measuring points in the rock; the steel bar meter is arranged on the upper surface of the concrete, 1 measuring points upstream and 1 measuring points downstream. A total of 77 sets of monitoring instruments were buried, including 33 sets of anchor stress meter, 33 sets of seam measuring meter and 11 sets of steel bar stress meter.

\section{Monitoring during excavation period}

Relying on the rock-bolted crane girder of the project, it took about one and a half years to complete the excavation from the deployment of monitoring equipment to the cavern of the hydropower station. Figure 3 is transverse section of the excavation stage of the main powerhouse.
After the excavation of the III layer of the main powerhouse is completed, the construction of rock-bolted crane girder is started, and then the lower excavation of the IV layer and below.

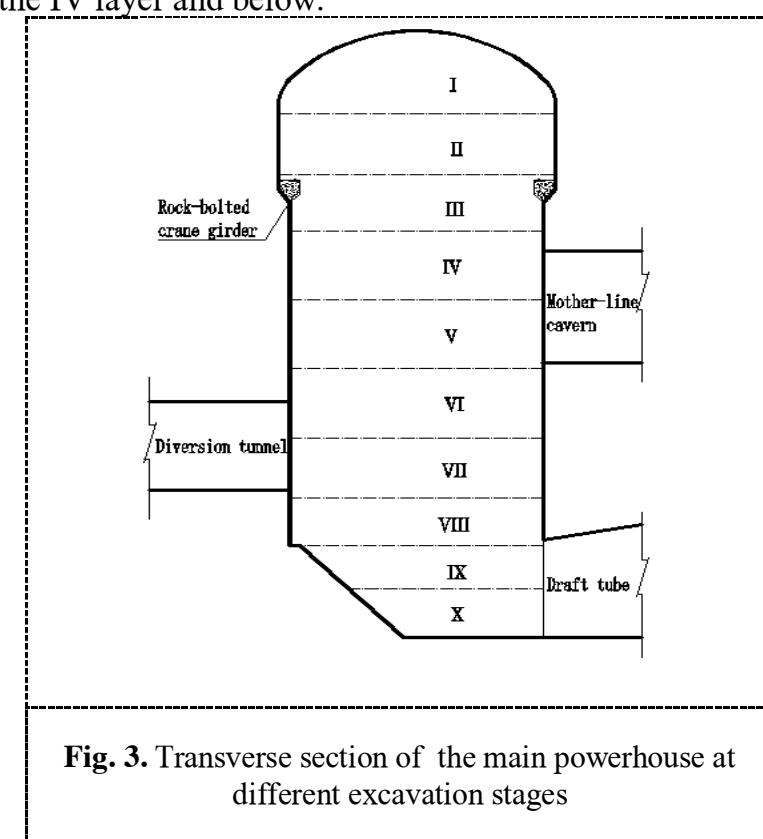

1) Opening and closing values between rock-bolted crane girder and rock wall

Statistics of the opening and closing values of all effective measuring points of the measuring seam meter, as shown in Table 1, The opening and closing values were all between- $0.5 \mathrm{~mm}$ and $2.5 \mathrm{~mm}$, and the change was basically stable. The opening and closing values of $87.9 \%$ measuring points were within $1.5 \mathrm{~mm}$.

Table 1. Opening and closing values distribution of seam measuring meter

\begin{tabular}{ccccccc}
\hline $\begin{array}{c}\text { Range of } \\
\text { measurement } \\
(\mathrm{mm})\end{array}$ & $\leq 0.5$ & $\begin{array}{c}0.5 \sim \\
1\end{array}$ & $\begin{array}{c}1 \sim \\
1.5\end{array}$ & $\begin{array}{c}1.5 \sim \\
2\end{array}$ & $\geq 2$ & Total \\
\hline $\begin{array}{c}\text { Percentage of } \\
\text { total (\%) }\end{array}$ & 45.45 & 33.33 & 9.09 & 6.07 & 6.06 & 100 \\
\hline
\end{tabular}

The section with large values of opening and closing of rock-bolted crane girder is analyzed, and the variation curve of the opening and closing values with time is 
shown in Figure 4. The excavation of the powerhouse below rock-bolted crane girder has the greatest influence on the opening and closing values. With the excavation of the powerhouse, there is a persistent trend of slow increase about the opening and closing values. With the end of the powerhouse excavation, the opening and closing values tends to converge. The opening and closing values is most affected by the excavation of mother-line cavern.

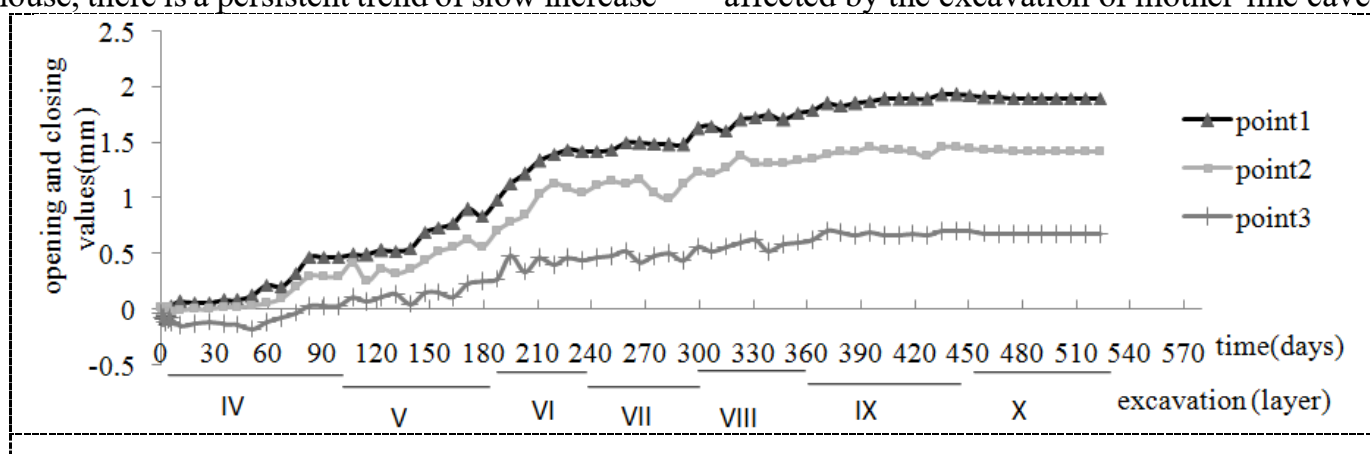

Fig.4. Opening and closing curves of the seam measuring meter following excavation

2) Steel bar stress monitoring

Statistical analysis of all steel bar stress, as shown in Table 2, the stress is less than $35 \mathrm{MPa}$, the proportion of each measuring range is uniform, the change of steel bar stress is relatively stable.

Table 2. Distribution table of steel bar stress

\begin{tabular}{cccccccc}
\hline Range of measurement $(\mathrm{MPa})$ & $\leq 5$ & $5 \sim 10$ & $10 \sim 20$ & $20 \sim 30$ & $30 \sim 35$ & $\geq 35$ & Total \\
\hline Percentage of total $(\%)$ & 18.18 & 18.18 & 27.27 & 18.18 & 18.18 & 0.00 & 100 \\
\hline
\end{tabular}

3) Anchor stress monitoring

Statistical analysis of all anchor stress, as shown in Table 3, the stress of most anchors is within $-50 \mathrm{MPa} \sim$ $100 \mathrm{MPa}$, which accounts for $77.12 \%$ of the total. Take the nearest tensile anchor bar in the section for analysis, as shown in Fig. 5, The increase of anchor stress is mainly influenced by the deformation adjustment of surrounding rock excavated from the lower part of rock-bolted crane girder, the IV layer excavation has the greatest influence on the anchor stress. With the excavation boundary is far away from rock-bolted crane girder, the anchor stress tends to be stable.

Table 3. Table of anchor stress distribution

\begin{tabular}{cccccccc}
\hline Range of measurement $(\mathrm{MPa})$ & $-50 \sim 50$ & $0 \sim 100$ & $100 \sim 300$ & $300 \sim 500$ & $500 \sim 600$ & $>600$ & Total \\
\hline Percentage of total $(\%)$ & 25.42 & 51.69 & 15.25 & 6.78 & 0.86 & 0 & 100 \\
\hline
\end{tabular}

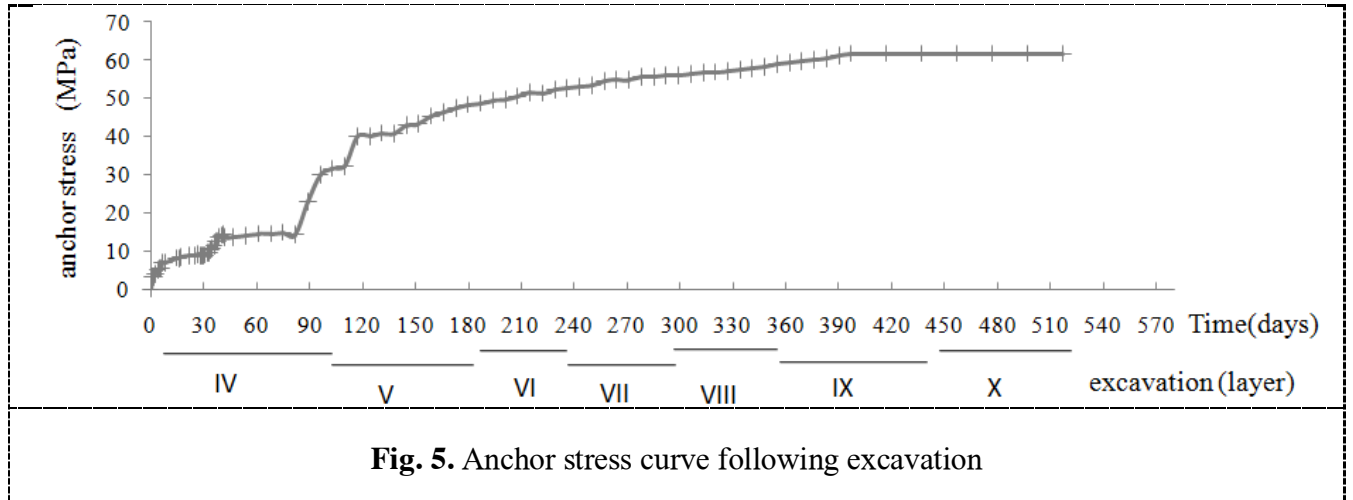

\section{Load-bearing test monitoring}

When bridge crane is in operation, the rock-bolted crane girder and the surrounding rock may continue to deform on the basis of excavation deformation, and its stress state will also change. In order to ensure the safety of the structure in use, the static and dynamic load test of rock-bolted crane girder must be carried out before the bridge crane is hoisted. Through the bridge crane step by step loading operation, including no-load, 25\%, 50\%, $75 \%, 100 \%, 110 \%$, monitoring rock-bolted crane girder and side wall monitoring equipment data changes, analyzing and testing the safety of rock-bolted crane girder structure. Figure 6 is a test photo of rock-bolted crane girder. 


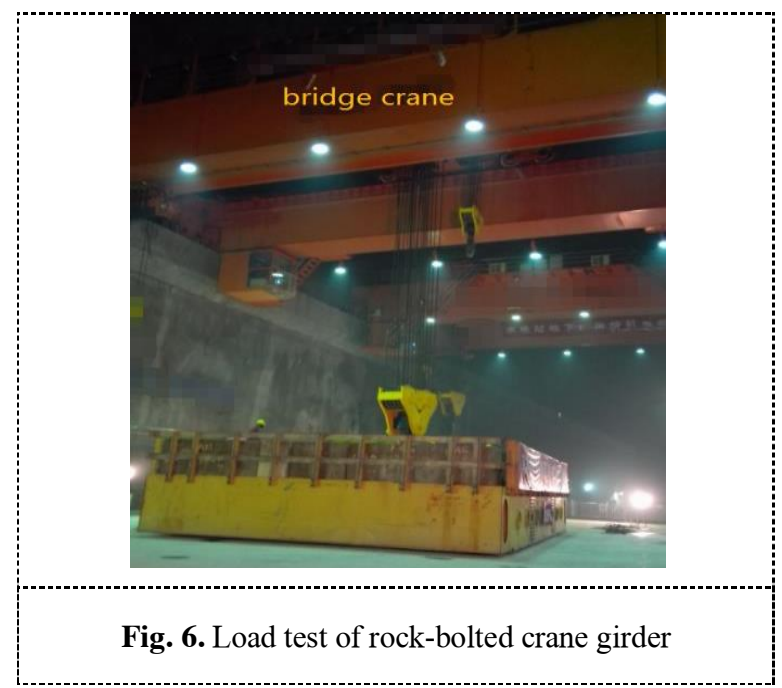

During the whole test, the change value of every equipment embedded in the rock-bolted crane girder is very small, the maximum change value of opening and closing is only $0.10 \mathrm{~mm}$, the maximum change value of steel bar stress is only 5.0 $\mathrm{MPa}$, the maximum change value of tension stress is $21 \mathrm{MPa}$, and the maximum change value of compression stress is $18 \mathrm{MPa}$, the value of multi-point displacement meter did not change. The accumulative maximum Opening and closing value is 2.3 $\mathrm{mm}$, the accumulative maximum steel bar stress value is 37.3 MPA, the accumulative maximum anchor stress value is 590.6 MPA. The cumulative monitoring results during each load test stage are shown in Table 4, All the measured values of the monitoring instruments are in design threshold.

Table 4. Table of monitoring results

\begin{tabular}{cccccccccc}
\hline Cumulative aximum & $\begin{array}{c}\text { Before } \\
\text { the test }\end{array}$ & no-load & $25 \%$ & $50 \%$ & $75 \%$ & $100 \%$ & $110 \%$ & $\begin{array}{c}\text { After the } \\
\text { test }\end{array}$ & $\begin{array}{c}\text { Criteria for } \\
\text { evaluation }\end{array}$ \\
\hline $\begin{array}{c}\text { Opening and closing value } \\
\text { of joint meter }(\mathrm{mm})\end{array}$ & 2.24 & 2.26 & 2.26 & 2.26 & 2.31 & 2.31 & 2.31 & 2.35 & $<4 \mathrm{~mm}$ \\
\hline Steel bar stress $(\mathrm{MPa})$ & 34.2 & 37.3 & 37.3 & 37.3 & 36.3 & 37.3 & 37.3 & 36.30 & $<300 \mathrm{MPa}$ \\
\hline Anchor stress $(\mathrm{MPa})$ & 589.8 & 589.8 & 590.1 & 588.6 & 590.6 & 590.4 & 590.4 & 588.90 & $<700 \mathrm{MPa}$ \\
\hline
\end{tabular}

Before, during and after the test, inspections were performed on the traffic cave, the installation room, the mother-line cavern and the rock-bolted crane upstream and downstream etc. there was no cracking of concrete, the adjacent structure was not damaged, and no unusual sound was heard. No new cracks were found on the surface of the rock-bolted crane, and the original cracks remained unchanged.

\section{Conclusion}

According to the monitoring results of rock-bolted crane girder, during excavation and unloading of the cavern, the monitoring instruments of rock-bolted crane girder are basically stable, the distribution of the measured values conforms to the normal law of the underground powerhouse, and there is no large data under the layered surrounding rock, this shows that even if the lamellar surrounding rock, under the action of a large number of bolts, rock-bolted crane girder basically forms a good integrity with the surrounding rock. Crane load is a small local load compared with the stress release of surrounding rock excavation, so it has little effect on the stress and stability of surrounding rock during the loading test, as long as the stability of surrounding rock itself is guaranteed, and can control the deformation in the allowed threshold, then the safety of rock-bolted crane girder of the underground powerhouse under the layered surrounding rock has no particularity.

\section{Acknowledgments}

This work was financially supported by the major science and technology project of Northwest Engineering Corporation Limited, Power China. In the meantime, we express thanks to our colleagues for their help and technical support.

\section{References}

1. R. Lien, J. Kristiansen, and L.S. Pran: International Water Power and Dam Construction (1990).

2. J. Fu, Y.C. Liu, and Q. Sheng: Chinese journal of rock mechanics and engineering (2001).

3. A.Q. Wu, J.M. Wang, and Z. Zhou: Journal of Rock Mechanics and Geotechnical Engineering (2016).

4. M. Wang, H.B. Li, and J. Han: Engineering Failure Analysis (2019).

5. S. H. Mei: Institute Of Rock And Soid Mechanics, Chinese Academy Of Sciences (2008). 